\title{
Study on dynamic characteristics of silt solidified soil caused by train operation
}

\author{
Hongwei Peng ${ }^{1}$, Chaofeng $\mathrm{Cao}^{2}$ \\ The Construction Engineering Company of CTCE Group, Hefei, China \\ ${ }^{1}$ Corresponding author \\ E-mail: ${ }^{186365034 @ q q . c o m, ~}{ }^{2}$ tou1479@foxmail.com
}

Received 28 April 2019; accepted 9 May 2019

DOI https://doi.org/10.21595/vp.2019.20755

Check for updates

Copyright (C) 2019 Hongwei Peng, et al. This is an open access article distributed under the Creative Commons Attribution License, which permits unrestricted use, distribution, and reproduction in any medium, provided the original work is properly cited.

\begin{abstract}
With the rapid development of railway construction, many railway projects often cross the soft ground. The initial water content of the silt is too high to be directly applied to the engineering practice. In order to improve the engineering property of the silt, the corresponding precipitation treatment measures should be taken according to the different initial water content of the silt to ensure the safety of the project. This article relying on Shilong railway freight yard container project that contain silt soil to conduct in situ curing technology research, the vibration response characteristics of the stabilized soil was studied before and after curing. The results showed that silt solidified soil has a significant attenuation effect on vibration energy. Increasing the proportion of curing agent can enhance the vibration isolation effect of silt solidified soil.
\end{abstract}

Keywords: dynamic, silt solidified soil, vibration, train operation.

\section{Introduction}

The initial water content of silt is too high to be directly applied to engineering practice. For the treatment of shallow silt, methods such as improved soil filling and in situ solidification can be adopted. Although the improved soil filling method has certain advantages in cost, the land acquisition and transportation cost of abandoned soil sites are huge, and the surrounding soil source is tense, so the replacement and improved soil filling cannot be realized, and the in-situ solidification of silt has more advantages [1]. In addition, curing technology can combine heavy metals and other curing technologies, which is conducive to environmental protection and sustainable development [2].

There are three ways of silt curing technology: 1) strong compaction, 2) high temperature sintering, and 3) method of adding curing agent [3]. However, the compaction equipment is expensive in cost, low in efficiency and limited in high-temperature sintering capacity. Therefore, it is of more practical significance and social as well as economic benefits to adopt the method of adding hardening agent to reduce the compressibility and moisture content of soil and improve its bearing capacity [4].

Therefore, in order to ensure construction site safety, shorten construction period, and reduce construction cost, this article relying on Shilong railway freight yard container project that contain silt soil to conduct in situ curing technology research, the vibration response characteristics of the stabilized soil was studied before and after curing. The optimization of solidification for silt soil has been proposed with important theoretical and realistic significance.

\section{Project description}

Shilong railway freight yard container project is located in the south-central Guangdong Province, China, and on the east bank of the Pearl River estuary, close to Dongguan city, Boluo county, Huizhou city, and Zengcheng district of Guangzhou city. It is about $69 \mathrm{~km}$ from the center of Guangzhou city, about $13 \mathrm{~km}$ from the center of Dongguan city, and about $60 \mathrm{~km}$ from the center of Huizhou city. The construction of this project is an important part of Shenzhen-Dongguan-Huizhou economic circle, a key hub and international gateway connecting 
the inland area of Guangdong with Hong Kong, Southeast Asia and even the world. It is an important rear base connecting "One Belt and One Road" which has great significance and role.

A large number of reservoirs are distributed in the project site, with silt and silty clay at the bottom, and the distribution thickness ranges from 0.5 to $3 \mathrm{~m}$. Therefore, in order to ensure the safe completion of Shilong railway freight yard container project, it is necessary to carry out in situ solidification technology research of silt.

\section{Numerical model}

Because the ground vibration caused by train is weak, the strain of foundation soil is generally less than $10^{-4} \mathrm{~m}$, so the foundation soil can be regarded as linear elastic medium approximately. The vibration source of train belongs to broadband random excitation in essence, so the ground vibration generated by it also has similar characteristics. In order to effectively simulate the characteristics of ground vibration caused by train, the size of its finite element model, the selection of element size, damping parameters and the determination of excitation load are of great importance. Based on the above factors, the numerical analysis model is established in this chapter.

\subsection{Train force}

For the simulation of train load, the following factors should be considered: 1) the dynamic performance of the train, 2) influence of train speed, 3) influence of track irregularity, 4) influence of uneven wear on top surface of rail, 5) continuous irregularity caused by eccentric wheel mounting, and individual irregularity caused by uneven wear of wheel tread [5].

According to many years of theoretical research and experimental work, the main reason of vertical wheel-rail force is caused by various irregularity and local blemish around the wheel. The experiment also shows that the vertical wheel-rail force mainly occurs in three frequency ranges: 1) the low frequency range $(0.5 \mathrm{~Hz}$ to $10 \mathrm{~Hz})$. Almost all produced by the relative motion of the car body to the suspension part, 2) intermediate frequency range $(30 \mathrm{~Hz}$ to $60 \mathrm{~Hz})$. Because of the springback effect of the unsprung wheel-set mass on the rail, 3$)$ high frequency range $(100 \mathrm{~Hz}$ to $140 \mathrm{~Hz}$ ) is generated because the movement of the rail is resisted by the contact surface of the wheel and rail. The measured results show that the wheel-rail force is severe in the intermediate frequency range, and the high frequency range mainly affects the dynamic response of the vehicle body.

Eq. (1) proposes an excitation force corresponding to high, medium and low frequency, reflecting uneven, additional dynamic load and rail surface waveform abrasion effect to simulate the interaction between wheel and rail, namely train load, and fully consider the moving superposition combination of train wheelset force on the line and the decentralized transfer factors of rail and sleeper:

$F(t)=k_{1} k_{2}\left(P_{0}+P_{1} \sin \omega_{1} t+P_{2} \sin \omega_{2} t+P_{3} \sin \omega_{3} t\right)$,

where, $k_{1}, k_{2}$ is the superposition coefficient and the dispersion coefficient. $P_{0}$ is the wheel static load. $P_{1}, P_{2}$ and $P_{3}$ are vibration loads corresponding to a typical value in the control condition.

Let the train's unsprung mass be $M_{0}$, then the corresponding vibration load amplitude is:

$P_{i}=M_{0} a_{i} \omega_{i}^{2}$

where $M_{0}$ represents the unsprung mass. $a_{i}$ is the height of the geometric unsmooth vector corresponding to the unsteady control condition, which reflects the road condition. $\omega_{i}$ is the circular frequency of vibration.

According to the calculation conditions, the train load simulation equation selected in this chapter is: 


$$
F(t)=1.08 \times(20+0.3701 \sin 31.42 t+0.6940 \sin 157.08 t+0.2024 \sin 392.7 t) .
$$

\subsection{Track structure}

The track structure model is composed of rail, sleeper and ballast. The track adopts $60 \mathrm{~kg} / \mathrm{m}$, $\mathrm{U} 75 \mathrm{~V}$ hot rolled steel track, the gauge is $1435 \mathrm{~mm}$, the whole process of seamless line. Sleeper is set at $1680 \mathrm{~km}$. The ballast bed is $0.45 \mathrm{~m}$ thick. Double ballast bed is adopted. The upper ballast thickness of the surface layer is $0.25 \mathrm{~m}$, and the first-class ballast is adopted. The lower level ballast thickness is $0.20 \mathrm{~m}$, and coarse sand and medium sand are adopted. The top width of the bed is $3.3 \mathrm{~m}$, and the slope rate is $1: 1.75$. The finite element model of track and sleeper is shown in Fig. 1, and the relevant parameters are shown in Table 1.

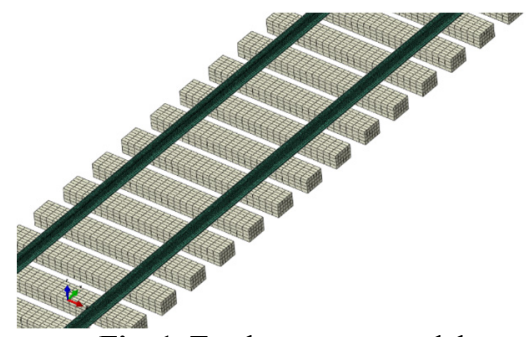

Fig. 1. Track structure model

Table 1. Physical property parameters of track structure model

\begin{tabular}{|c|c|c|c|}
\hline- & Modulus of elasticity $(\mathrm{MPa})$ & Poisson's ratio & Density $\left(\mathrm{kg} / \mathrm{m}^{3}\right)$ \\
\hline Rail & 210000 & 0.25 & 7850 \\
\hline Sleeper & 30000 & 0.2 & 2400 \\
\hline Upper ballast & 300 & 0.35 & 1800 \\
\hline Lower level ballast & 300 & 0.35 & 2200 \\
\hline
\end{tabular}

\subsection{Soil}

Because the vibration caused by metro trains is mainly transmitted through the surface and the impact on the foundation soil mainly occurs in the elastic range, the foundation soil model can be simplified as homogeneous soil and the linear elastic model can be used for simulation. The main physical and mechanical parameters of the foundation soil of the depot are shown in Table 2 . The size of the established finite element model of foundation soil is $130 \times 130 \times 55$ (length $\times$ width $\times$ height, unit: $\mathrm{m}$ ), as shown in Fig. 2 .

Table 2. Physical property parameters of soil model

\begin{tabular}{|c|c|c|c|c|c|}
\hline Soil layer & Density $\left(\mathrm{g} / \mathrm{cm}^{3}\right)$ & Elasticity modulus $(\mathrm{MPa})$ & Poisson's ratio $v$ & $V_{p}(\mathrm{~m} / \mathrm{s})$ & $V_{S}(\mathrm{~m} / \mathrm{s})$ \\
\hline Silt & 1.65 & 50 & 0.30 & 257 & 124 \\
\hline Silt stabilized soil & 1.93 & 300 & 0.25 & 540 & 260 \\
\hline
\end{tabular}

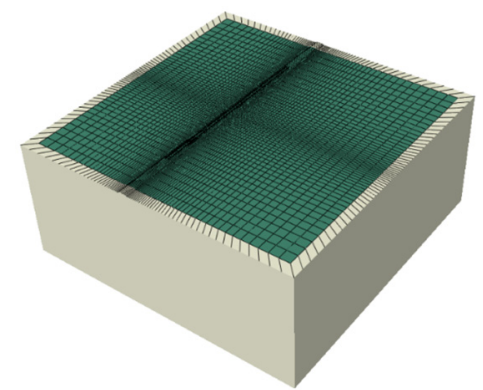

Fig. 2. Soil model 


\subsection{The boundary conditions}

When the finite discrete model is used to simulate the infinite foundation, the biggest problem of the artificial truncated boundary is that the wave is reflected on the interface of the artificial boundary, so that the energy is transmitted back to the analysis region and cannot be propagated to infinity, resulting in the simulation distortion. The solution is to set the soil of the outermost element as infinite element and absorb the radiation energy of the plane body wave by introducing damping force on the boundary, so as to prevent the reflection of the wave and interfere with the calculation of the model.

\section{Results}

The surface vibration results before and after silt stabilized are compared, and the vibration characteristics before and after silt stabilized are shown in Fig. 3.

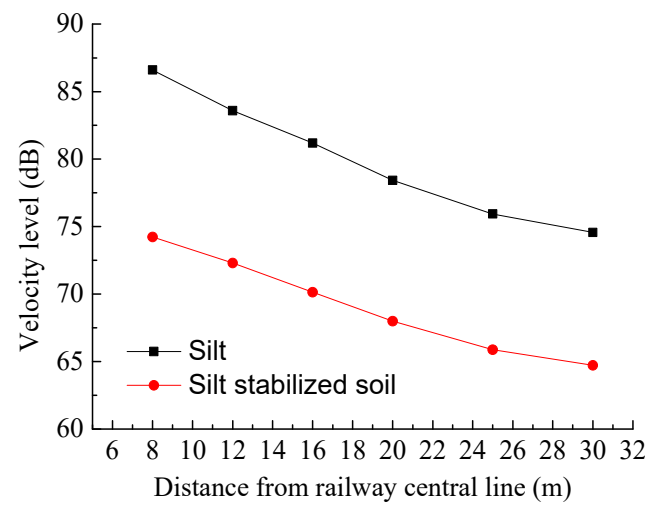

Fig. 3. Comparison of vibration response of silt and silt stabilized soil

It can be seen from the Fig. 3 that the attenuation effect of silt reinforced soil on vibration energy is quite significant. It can reduce the ground vibration level by about $10-12.5 \mathrm{~dB}$ within the range of $30 \mathrm{~m}$ from the track central line, and the closer it is to the track central line, the greater the vibration level attenuation will be.

In order to study the influence of proportion of curing agent admixture on the vibration effect, the ratios of $10 \%, 20 \%, 30 \%$ and $40 \%$ were selected for comparative analysis. The vibration reduction effect is shown in Table 3.

Table 3. Effect of curing agent with different proportion

\begin{tabular}{|c|c|}
\hline Proportion & Vibration absorption effect $(\mathrm{dB})$ \\
\hline $10 \%$ & 3.4 \\
\hline $20 \%$ & 8.7 \\
\hline $30 \%$ & 12.1 \\
\hline $40 \%$ & 12.9 \\
\hline
\end{tabular}

It can be seen that the effect of vibration isolation increases with the increase of the proportion of curing agent, but after increasing to a certain proportion, the effect of vibration isolation does not increase obviously.

\section{Conclusions}

This article relying on Shilong railway freight yard container project that contain silt soil to conduct in situ curing technology research, the vibration response characteristics of the stabilized soil was studied before and after curing. The conclusions can be drawn as: 
1) Silt solidified soil has a significant attenuation effect on vibration energy. It can reduce the ground vibration level by about $10-12.5 \mathrm{~dB}$ within the range of $30 \mathrm{~m}$ from the track central line, and the closer it is to the track central line, the greater the vibration level attenuation will be.

2) Increasing the proportion of curing agent can enhance the vibration isolation effect of silt solidified soil.

\section{References}

[1] Cai G., Liu S., Du, Y., Zhang D., Zheng X. Strength and deformation characteristics of carbonated reactive magnesia treated silt soil. Journal of Central South University, Vol. 22, 2015, p. 1859-1868.

[2] Su Q., Xu Y., Zhang F. The present research and foreground expectation of soil stabilizer. Journal of Heilongjiang Institute of Technology, Vol. 3, 2005, p. 1-10.

[3] Maher A., Douglas W. S., Yang D., Jafari F., Schaefer V. R. Cement deep soil mixing (CDSM) for solidification of soft estuarine sediments. Marine Georesources and Geotechnology, Vol. 25, 2007, p. 221-235.

[4] Park J. H., Lee J. S. Characteristics of elastic waves in sand-silt mixtures due to freezing. Cold Regions Science and Technology, Vol. 99, 2014, p. 1-11.

[5] Galvín P., Romero A., Dominguez J. Vibrations induced by HST passage on ballast and non-ballast tracks. Soil Dynamics and Earthquake Engineering, Vol. 30, 2010, p. 862-873. 